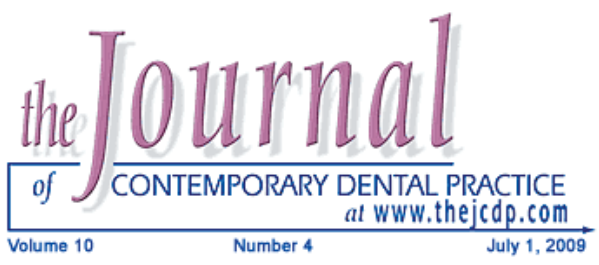

\title{
Fiber-reinforced Onlay Composite Resin Restoration: A Case Report
}

Sufyan Garoushi, BDS, PhD; Akikazu Shinya, DDS, PhD; Akiyoshi Shinya, DDS, PhD; Pekka K. Vallittu, DDS, PhD

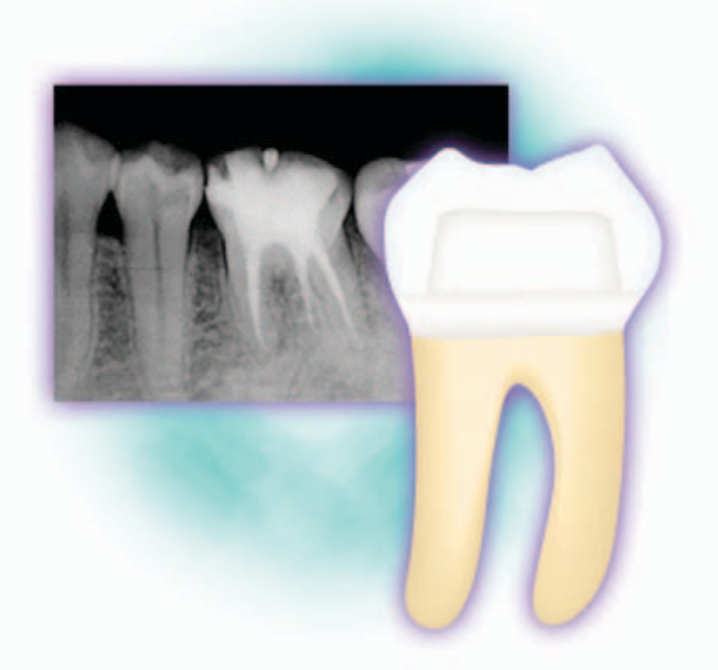

Abstract

Aim: The purpose of this case report is to describe the clinical procedure for fabricating fiber-reinforced composite (FRC) onlay composite resin restorations using a FRC as the substructure.

Background: A variety of therapeutic modalities are available to restore teeth with moderate coronal defects in the posterior region of the mouth. For patients who refuse complete crown restorations or when minimal tooth reduction is preferred, a FRC restoration can be a good alternative to conventional restorative techniques.

Case Report: A 42-year-old female patient presented with an endodontically treated mandibular right first molar with extensive destruction of the coronal tooth structure. To conserve the remaining tooth structure a FRC resin core substructure was fabricated and veneered with Ceramage dentin and enamel hybrid composite to create the final restoration.

Summary: FRC restorations using adhesive technology appears to be a promising restorative option. However, further clinical investigation will be required to provide additional information on this technique. Based on the clinical and radiographic findings in the present case, the fabrication of a conventional crown was avoided in order to conserve the remaining tooth structure.

(C) Seer Publishing 
Clinical Significance: The restoration of badly damaged teeth is a challenge for clinicians when cast crown restorations are not an option for the patient. The use of FRC restorations along with adhesive technology may be a rational restorative alternative in the near future.

Keywords: Case report, composite resin, fiber-reinforced composite, FRC

Citation: Garoushi S, Shinya A, Shinya A, Vallittu PK. Fiber-reinforced Onlay Composite Resin Restoration: A Case Report. J Contemp Dent Pract 2009 July; (10)4:104-110.

\section{Introduction}

Various restorative alternatives are currently available to restore teeth with moderate coronal defects in the posterior region of the dentition. Selection of the best alternative is dependent on the evaluation and satisfaction of several criteria. Routine use of metal-ceramic crowns rather than using gold alloy partial crowns and onlay restorations necessitate the removal of healthy enamel and dentin.

Adhesively bonded ceramic onlays have been used as an alternative to minimize the removal of tooth structure. The most success has been limited to anterior teeth using ceramic onlays in the form of porcelain veneers, ${ }^{1,2,3}$ while ceramic onlays have been less successful for restoring posterior teeth. ${ }^{4,5}$ This is not surprising as their fracture resistance and abrasiveness are clearly inferior to gold alloys. Despite this shortcoming, glass-containing ceramics have been widely used because of their esthetic qualities. ${ }^{6}$

Particulate filler composite resin (PFC), once only considered a treatment option for anterior teeth, has been increasingly used in wider applications. As the mechanical properties and wear resistance of existing PFCs have improved, their use has expanded to include posterior intracoronal as well as extracoronal restorations including complete crowns and fixed partial dentures. ${ }^{7}$

Indirect restorations in the form of inlays/onlays have been used for almost 25 years. They were introduced with the intent of overcoming problems related to the lower degree of conversion during polymerization associated with direct posterior PFCs placed using conventional incremental techniques. The most common problems were various types of fractures in high stressbearing areas. ${ }^{8}$ The indirect technique offered hope of improving the load-bearing capacity of composite resin restorations by increasing the degree of conversion obtained by post-curing the restorations in the laboratory. However, extraoral polymerization of composite followed by cementation appears to only improve the marginal fit and minimize contraction stress. ${ }^{9}$ The relatively high brittleness and low load-bearing capacity of current PFCs still hinder their use in large stress-bearing restorations..$^{10-12}$ As a result, there is considerable need for improved mechanical properties, especially load-bearing capacity, while retaining the esthetic properties of PFCs.

Parallel to the evolution of adhesive materials and techniques, the concept of using fiber-reinforced composite resin (FRC) has been introduced. . $^{13-15}$ The mechanical advantages provided by FRCs are their flexural strength, fatigue strength, elastic modulus, and bond strength (of the fiber framework to veneering composites and resin luting cements). Additionally, FRCs are metalfree, esthetic, and allow a minimally invasive treatment technique even when using the direct treatment technique. However, FRCs have not meet a wide clinical acceptance until recently although they have been successful in the reinforcement of long-term restorations such as crowns and bridges. ${ }^{16,17}$ The issues limiting wide acceptance of FRCs were the sensitive clinical technique required and the mechanical properties of FRCs that were initially well below theoretical calculations and expectations. This was a result of low fiber content in the final restoration and an inadequate impregnation of the fibers with resin often due to their high viscosity. ${ }^{18}$

Manufacturers then offered industrial resin impregnated FRC materials in an effort to improve their clinical manipulation. One manufacturer 
(StickTech Ltd, Turku, Finland) created polymethyl methacrylate (PMMA)-dimethacrylate (BisGMA)-based semi-interpenetrating polymer (semi-IPN) matrix to address the problem. ${ }^{19}$ The semi-IPN improved the handling properties of FRC and allowed the surface of the FRC structure to be re-activated in order to create a durable bond during cementation of restorations fabricated in the laboratory to abutment teeth and to root canal posts. Bonding was also improved during the process of layering veneering composite on a FRC framework or when repairing existing FRC restorations.

Interestingly, recent laboratory studies have shown onlay restorations made from a combination of FRC as a substructure and PFC have a better load-bearing capacity than those obtained without FRC reinforcement. ${ }^{20,31}$

The present clinical work describes the use of a fiber-reinforced onlay composite resin restoration using FRC as substructure under a PFC, with the aim of improving the load-bearing capacity of the restoration without interfering with esthetics.

\section{Case Report}

\section{Diagnosis}

A 42-year-old female patient presented with an endodontically treated mandibular right first molar with extensive destruction of the coronal tooth structure (Figure 1).

Based on clinical and radiographic findings, the fabrication of a conventional crown was ruled out

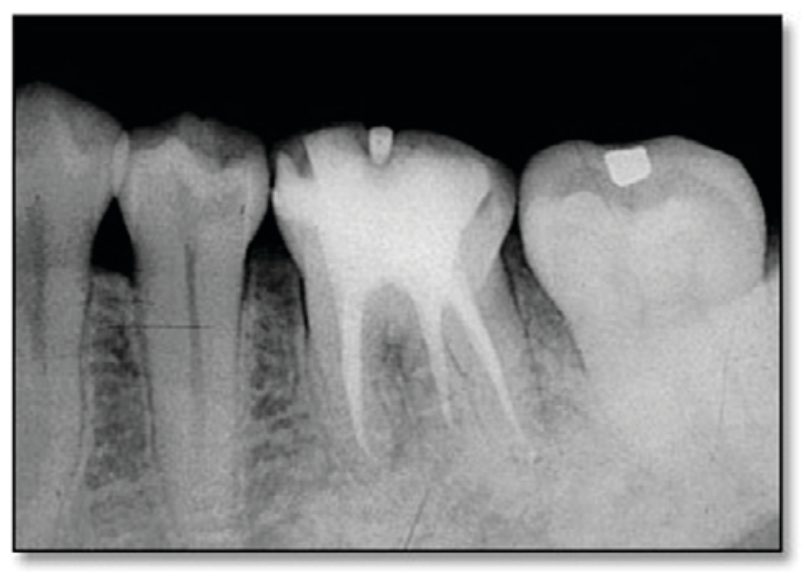

Figure 1. Preoperative radiograph. in order to conserve remaining tooth structure. The patient presented a favorable occlusion and an acceptable level of oral hygiene which provided a favorable environment for an indirectly fabricated fiber-reinforced post-onlay hybrid composite restoration.

\section{Treatment}

\section{Tooth Preparation}

Occlusal analysis using articulating paper was useful information for adhering to the biomechanical principles governing indirect cavity preparations to ensure occlusal and axial reductions were approximately $1.5 \mathrm{~mm}$ to provide sufficient space for placement of the fibers and composite resin veneer. ${ }^{22}$

Since the retention of the prosthesis was dependent on adhesive luting and cavity retention form, the walls of the cavity were flared between $6^{\circ}$ to $15^{\circ}$. The cervical margin was a shoulder style and all internal line angles were rounded (Figure 2).

\section{Impression and Temporization}

After tooth preparation, gingival retraction was carried out only at the mesial gingival floor prior to the impression, using Ultrapak ${ }^{\mathrm{TM}}$ gingival retraction cord (Ultradent Products, Inc., South Jordan, UT, USA). The cord was positioned 0.5 $\mathrm{mm}$ subgingivally and retained for five minutes. The cord was then carefully removed and a fullarch impression was made using Examixfine (regular) and Exafine (putty) elastomer materials

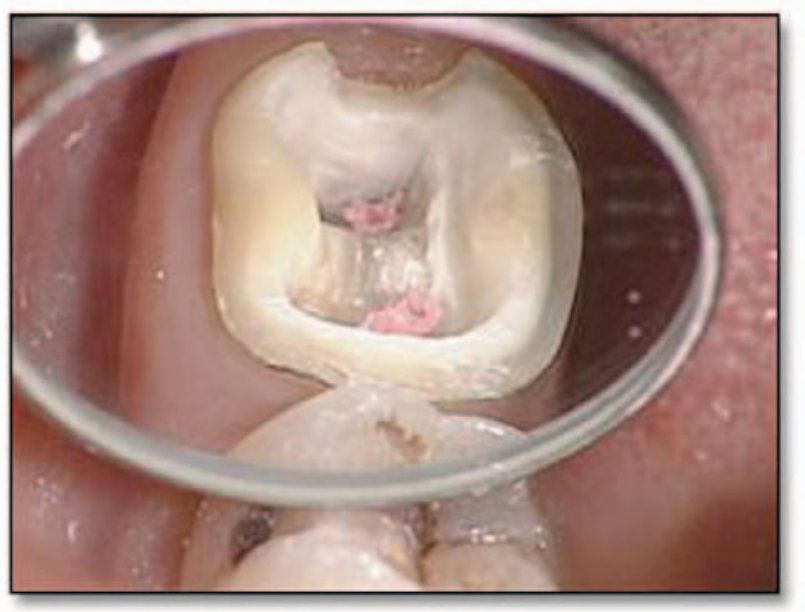

Figure 2. Occlusal view of the prepared tooth. 
(GC, Tokyo, Japan). The cavity preparation was provisionally restored using Unifast III chemical cure resin (GC, Tokyo, Japan). The shade of final veneered composite resin was selected using a vintage halo NCC shade guide (Shofu Inc, Kyoto, Japan).

\section{Prosthesis Fabrication}

Die stone (KerrLab, Orange, CA, USA) was poured and the casts were mounted in a semi-adjustable articulator (KaVo America, Lake Zurich, IL, USA). A thin coat of a rubber separating material (KerrLab, Orange, CA, USA) was painted on the die to within $1 \mathrm{~mm}$ of the finish line. The fiber substructure was constructed by using everStick pre-impregnated E-glass fibers (StickTech Ltd, Turku, Finland) embedded in Stick Resin, a polymer matrix of semi-IPN resin (StickTech Ltd, Turku, Finland) (Figure 3). Flow composite (Ceramage flowable composite resin, Shofu Inc, Kyoto, Japan) was used to seal the spaces between fiber frame and cavity walls.

Finally, the fiber substructure was finished (Figure 4), wetted with Stick resin, and veneered with Ceramage dentin and enamel hybrid composite (Figure 5).

The FRC-substructure and veneered composite resin were polymerized with a hand-held curing unit (Optilux 501, Kerr, CT, USA) for 40 seconds per layer of resin at a wavelength between 380 and $520 \mathrm{~nm}$ with a maximal intensity at $470 \mathrm{~nm}$ and a light irradiance of $800 \mathrm{~mW} / \mathrm{cm}^{2}$. Then the restoration was further post-cured in a light-curing oven (LicuLite, Dentsply, Dreiech, Germany) for 15 minutes.

\section{Try-in and Adhesive Luting}

The temporary restoration was removed with a scaler and the preparation was cleaned with polishing paste (Pressage, Shofu Inc, Kyoto, Japan) and a finishing brush (Merssage brush, Shofu Inc, Kyoto, Japan). The prosthesis was evaluated intraorally to assess marginal fit, occlusion, and esthetics before final cementation.

Luting an FRC prosthesis utilizes the technique identical to any bonded restorative procedure which includes: isolation of the abutment tooth, treatment of the inner surface of the FRC prosthesis, and treatment of the abutment tooth.

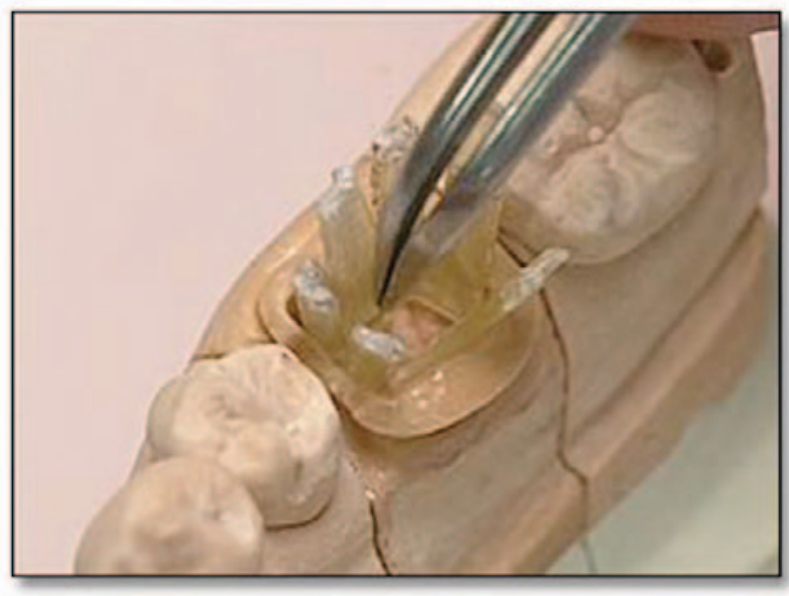

Figure 3. Build up of the fiber-substructure on the working die.

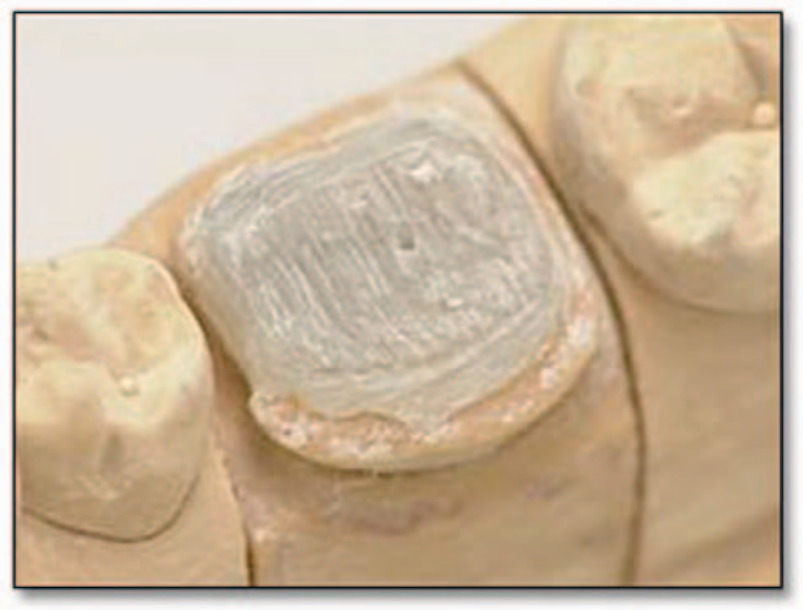

Figure 4. Fiber-substructure has been finished and checked on the working die.

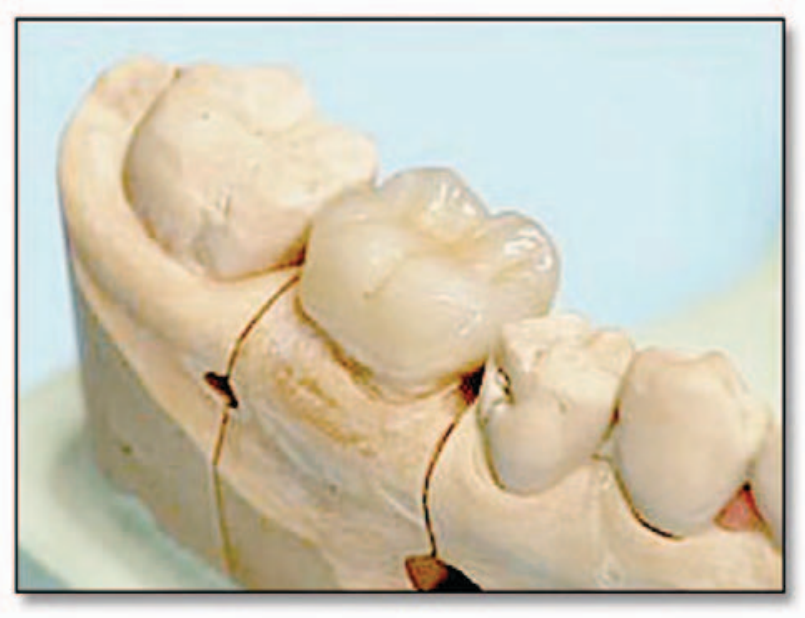

Figure 5. Marginal fit and morphology of the restoration were checked on the working die before luting. 


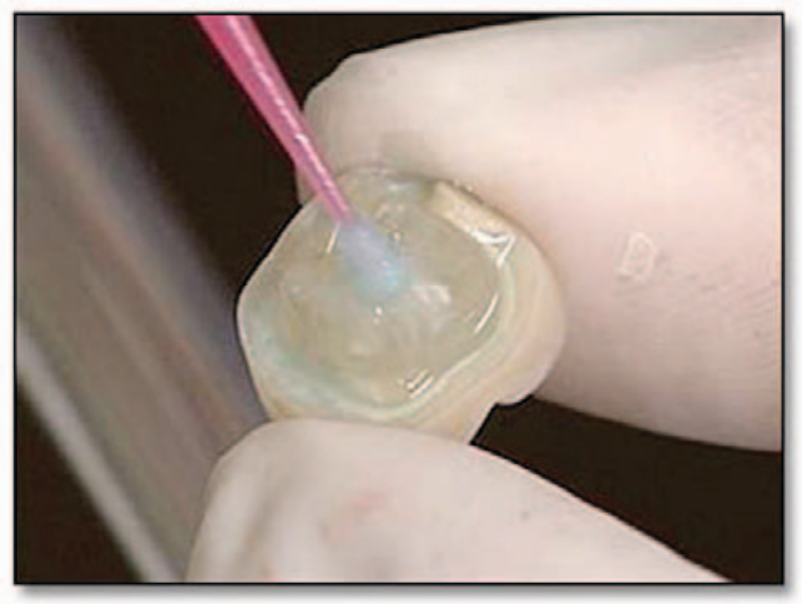

Figure 6. Reactivation the inner surface of FRC with a resin before cementation.

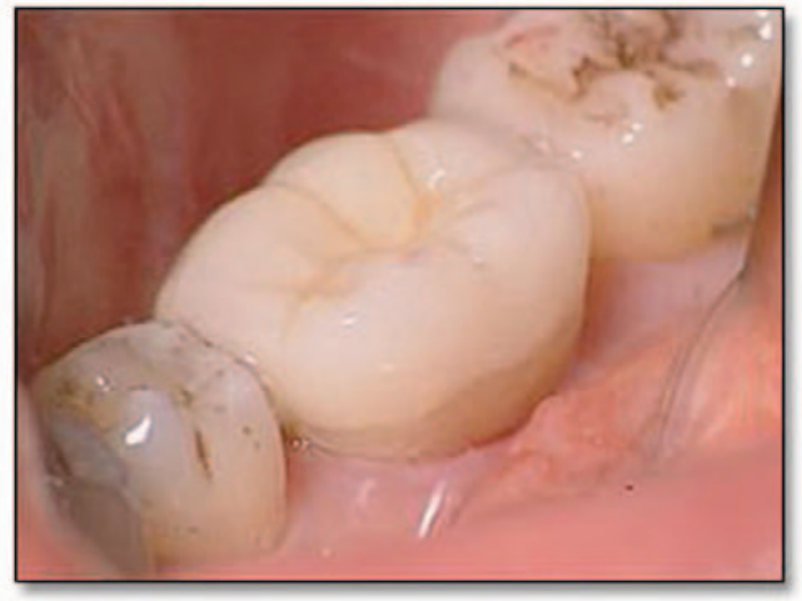

Figure 7. Occlusal view of the finished restoration.

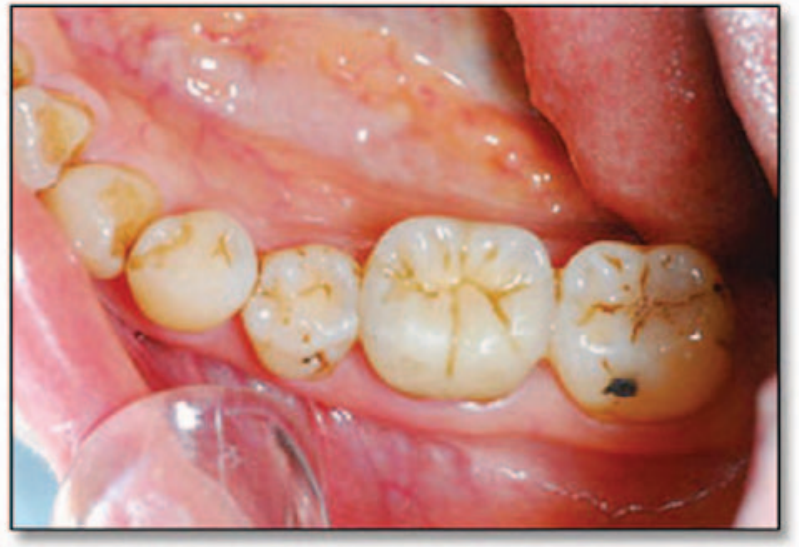

Figure 8. Occlusal view after three years follow up.
First, bonding sites were isolated with cotton rolls, although a rubber dam is recommended. Reactivation of the FRC bonding surface with a resin was carried out in order to create a durable bond with the cement (Figure 6). The FRC with a semi-IPN resin matrix adheres with resin composites by means of interdiffusion bonding.

Concurrently, the prepared tooth was etched with $37 \%$ phosphoric acid, rinsed, and lightly dried.

Then a Scotchbond multi-purposes adhesive layer (3M ESPE, St. Paul, MN, USA) was applied. The cementation of the restoration was done with Imperva Dual and anti-oxygen paste (Imperva Oxy-barrier, Shofu, Inc., Kyoto, Japan) following the manufacturer's instructions. After removing excess cement, adjusting the occlusion (group function) using articulating paper (Patterson Dental, St. Paul, MN, USA), the prosthesis was finished with Shofu 411 diamond burs (Shofu Inc., Kyoto, Japan) and polished using the Enhance polishing system (Dentsply GmbH, Konstanz, Germany) (Figure 7).

The treatment was accomplished in two visits. The outcome has been monitored over three years with no evidence of problems (Figure 8).

Patient interest in cosmetic and metal-free restorations in recent years has lead to the development of improved esthetic composite resins. The use of glass fibers as substructure in combination with composite resins has provided the appropriate mechanical strength for use in high stress bearing applications. Currently, acceptable success rates with long-term FRC restorations such as crowns and bridges have been reported. ${ }^{14,17,23}$ However, the importance of using high quality and proven materials in conjunction with proper clinical and laboratory techniques needs to be emphasized.

\section{Summary}

FRC restorations using adhesive technology appears to be a promising restorative option. However, further clinical investigation will be required to provide additional information on this technique. Based on the clinical and radiographic findings in the present case, the fabrication of a conventional crown was avoided in order to conserve the remaining tooth structure. 


\section{Clinical Significance}

The restoration of badly damaged teeth is a challenge for clinicians when cast crown restorations are not an option for the patient.
The use of $\mathrm{FRC}$ restorations along with adhesive technology may be a rational restorative alternative in the near future.

\section{References}

1. Dumfahrt $\mathrm{H}$, Schaffer $\mathrm{H}$. Porcelain laminate veneers. A retrospective evaluation after to 10 years of service: Part II - clinical results. Int J Prosthodont 2000; 13:9-18.

2. Friedman MJ. A 15-year review of porcelain veneer failure - a clinician's observations. Compend Contin Educ Dent 1998; 19:625-32.

3. Frankenberger R, Krämer N. Clinical performance of bonded leucite-reinforced glass ceramic inlays and onlays after eight years. Dent Mater 2005; 21:262-71.

4. Felden A, Schmalz G, Hiller KA. Retrospective clinical study and survival analysis on partial ceramic crowns: results up to 7 years. Clin Oral Investig 2000; 4:199-205.

5. Walls AW, Nohl FS, Wassell RW. Crowns and other extra-coronal restorations: Resin-bonded metal restorations. BDJ 2002; 193:135-42.

6. Gegauff AG, Garcia JL, Koelling KW, Seghi RR. Thermoplastic composites for veneering teeth a feasibility study. Dent Mater 2002; 18;479-85.

7. Freilich MA, Karmaker AC, Burstone CJ, Goldberg AJ. Development and clinical applications of a light-polymerized fiber-reinforced composite. J Prosthet Dent 1998; 80:311-18.

8. Burke FJ, Watts DC, Wilson NH, Wilson MA. Current status and rationale for composite inlays and onlays. Br Dent J 1991; 170:269-73.

9. Wendt SL, Leinfelder KF. The clinical evaluation of heat-treated composite resin inlays. J Am Dent Assoc 1990; 120:177-81.

10. Zandinejad AA, Atai M, Pahlevan A. The effect of ceramic and porous fillers on the mechanical properties of experimental dental composites. Dent Mater 2006; 22:382-7.

11. Wilder Jr. AD, Bayne SC, Heymann HO. Long-term clinical performance of direct posterior composites. Trans Acad Dent Mater 1996; 9:151-69.

12. $\mathrm{Xu} \mathrm{HH}$. Dental composite resins containing silica-fused ceramic single-crystalline whiskers with various filler levels. J Dent Res 1999; 78:1304-11.

13. Vallittu PK. A review of fiber-reinforced denture base resins. J Prosthodont 1996; 5:270-76.

14. Vallittu PK. Survival rates of resin-bonded, glass fiber-reinforced composite fixed partial dentures with a mean follow-up of 42-months: a pilot study. J Prosthet Dent 2004; 91:241-7.

15. Edwards KL. An overview of the technology of fiber-reinforced plastics for design purposes. Mater Des 1998; 19:1-10.

16. Freilich MA, Meiers JC. Fiber-reinforced composite prostheses. Dent Clin N Am 2004; 48:545-62.

17. Göhring TN, Roos M. Inlay-fixed partial dentures adhesively and reinforced by glass fiber: clinical and scanning electron microscopy analysis after five years. Eur J Oral Sci 2005; 113:60-9.

18. Vallittu PK. Some aspects of the tensile strength of unidirectional glass fiber-polymethyl methacrylate composite used in dentures. J Oral Rehabil 1998; 25:100-5.

19. Lastumäki TM, Lassila LV, Vallittu PK. Flexural properties of the bulk fiber-reinforced composite DC-Tell used in fixed partial dentures. Int J Prosthodont 2001; 14:22-6.

20. Garoushi S, Lassila LVJ, Tezvergil A, Vallittu PK. Fiber-reinforced composite substructure: load bearing capacity of an onlay restoration and flexural properties of the material. J Contemp Dent Pract 2006; 7:1-8.

21. Garoushi S, Lassila LVJ. Vallittu PK. Fiber-reinforced composite substructure: load bearing capacity of an onlay restoration. Acta Odontol Scand 2006; 64:281-85.

22. Corona SM, Garcia PS, Dibb-Palma RG, Chimello DT. Indirect aesthetic adhesive restoration with fiber-reinforced composite resin. Dental Update 2004; 31:482-84.

23. Freilich MA, Meiers JC, Duncan JP, Eckrote KA, Goldberg AJ. Clinical evaluation of fiber-reinforced fixed bridges. J Am Dent Assoc 2002; 133:1524-34. 


\section{About the Authors}

\section{Sufyan Garoushi, BDS, PhD}

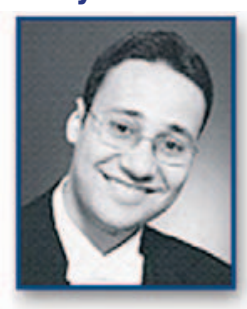

Dr. Garoushi graduated from Garuyons University in 1999 and received his $\mathrm{PhD}$ from Turku University in 2006. He is currently serving as a Postdoctoral Fellow in the Department of Prosthetic Dentistry and Biomaterials Science of the Institute of Dentistry at the University of Turku in Turku, Finland. His current research is focused on fiber-reinforced composite in dentistry.

e-mail: sufgar@utu.fi

\section{Akikazu Shinya, DDS, PhD}

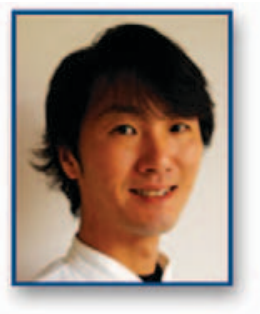

Dr. Shinya is a Researcher in the Department of Prosthetic Dentistry and Biomaterials Science of the Institute of Dentistry at the University of Turku in Turku, Finland and a Lecturer in the Department of Crown and Bridge of the School of Life Dentistry at Tokyo, The Nippon Dental University in Tokyo, Japan.

\section{Akiyoshi Shinya, DDS, PhD}

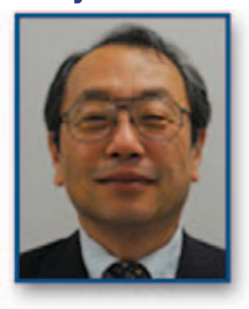

Dr. Shinya is a Professor in the Department of Crown and Bridge of the School of Life Dentistry at Tokyo, The Nippon Dental University in Tokyo, Japan.

\section{Pekka K. Vallittu, DDS, PhD}

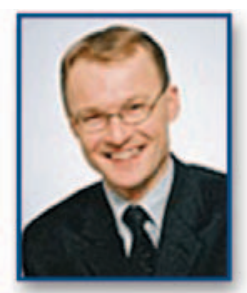

Dr. Vallittu is a Professor of Prosthodontics and Chairman of the Institute of Dentistry at the University of Turku, Finland. He received both his DDS and PhD from Kuopio University in 1994. He has served as a Visiting Scientist at the Scandinavian Institute of Dental Materials (NIOM) and has presented scientific lectures in 10 countries, including the USA, Canada, China, UK, Netherlands, and Japan. Dr. Vallittu has served as a referee to a number of international journals, edited 4 books, and published over 100 peer-reviewed articles. His primary research areas are fiberreinforced composites in dentistry and in other biomedical applications. 